\title{
Design of Sound and Place - Recent Studios
}

Marie-Paule Macdonald

University of Waterloo

\begin{abstract}
Urban public spaces and their associated architecture should be capable of eliciting responses from all of the human senses, yet traditionally urban and architectural designers rely primarily on visual display to persuade the public of the qualities of new proposals. As it becomes more common to u se a $v$ ariety of media to depict and simulate proposed urban spaces, d esigners and teachers of design look for ways to sensitize e merging designers to the full spectrum of sensations that inform potential users of a p ublic space. The design studios discussed in this paper bring together the issues of the design of the experience of $v$ isual and a ural settings, in an era of podcasts and ear-buds.

In order to address issues of sound and public space, the author selected examples from two a rchitectural design studios that took place in 2016 and 2018. Undergraduate students composed their own programs and projects to take into account the aural as well as visual qualities associated with their design intentions and a mbitions. The process began with a programming phase to designate performing and listening as interactions that constitute primary activities happening in the context of the proposed public built form and related urban space. The research continued with an exploration of the tectonics and materials of the projects. Preliminary field research located and mapped small centralized urban organizations related to the sonic: collectives and small businesses working, for example, in the areas of sound recording, radio and musical performance.

Drawing on the work of some thirty student projects, sited in North A merica and Europe, several schemes are discussed in terms of their innovative involvement with acoustic qualities as prime components of s patial experience. This speculation ranges from reuse and repurposing of underused existing structures in central downtown neighborhoods; to incorporating access to environments to house various instruments to be made available to p rospective users; to creating access, including features relevant to the experience of sound, a cross infrastructures that would o therwise have remained o bstacles to the pedestrian city. The project made propositions that extend to such fundament questions as addressing innovative approaches to maintaining well-being, or proposed institutions for the pursuit of research into sound, noise and music. Ultimately the proposals aimed for the design of contemporary spaces of g athering where individuals might share common public space, and collectively further the experience of communicating in large or small crowds, in both new and traditional ways.
\end{abstract}

\section{INTRODUCTION: THE 3RD YEAR STUDIO FRAMEWORK}

A quotation attributed to J ohann Wolfgang von Goethe, or Friedrich Schiller-architecture is frozen music-is a f amiliar response to a question asking about the relation between the domains. While a c liché, it is not an empty one-there is much to explore in the abstraction of the interval, rhythm, and expressive categories of timbre, volume and tone, or improvisation and 


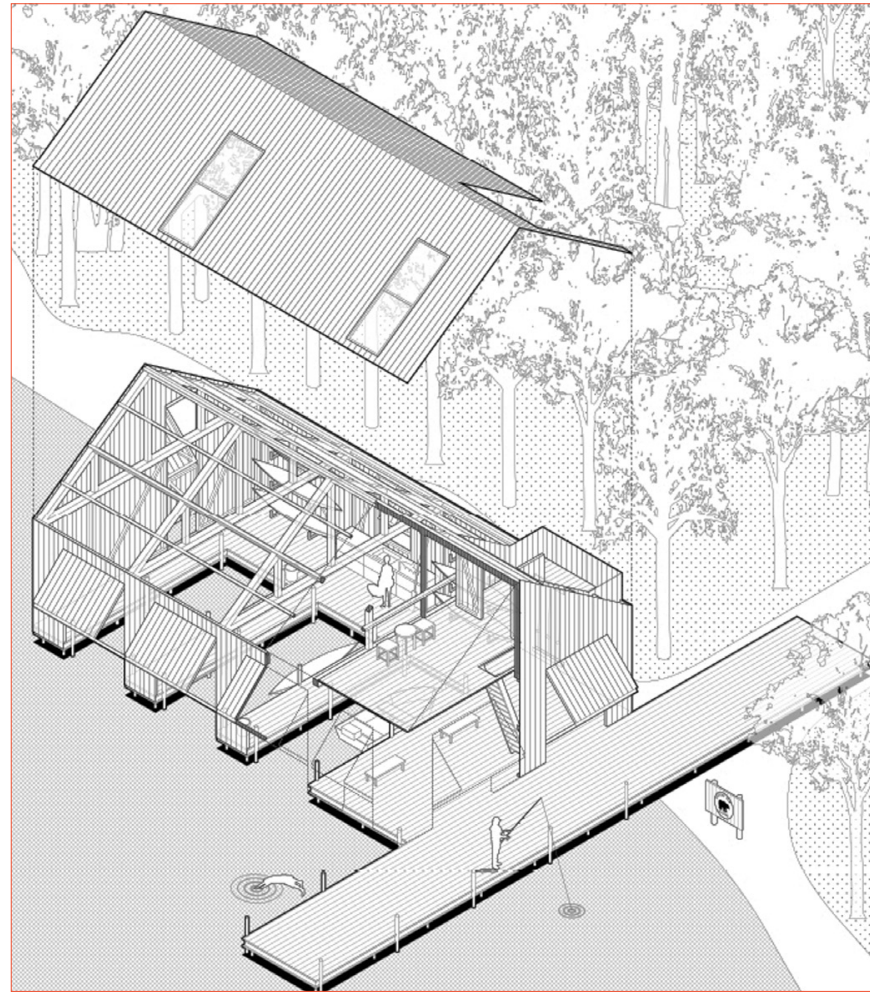

Figure 1. Zachary Ropel-Morski, Sleeping Bear Studio, Big Island, Oak Lake. Ontario, Canada

notation, not to mention echo, reverb or feedback. In terms of difference, the lack of frontality of hearing, its three-dimensional and 'always-on' qualities are important aspects of I istening and the acoustic environment, as noted by R. Murray Schaffer, the Canadian composer who coined the term soundscape.

The s tudio o pened a w ide frame of reference, from composers such as futurist noise artists, Luigi Russolo, and his Intonarumori or noise instruments, to the mid-century abstract and found noise of Delia Derbyshire, of the BBC Radiophonic Workshop (composer of the television series Dr. Who theme) to modern composer and architect Xenakis. Some of the reference texts included theoretical writing by Jacques Attali, and a nalysis of the experimental practices of musician and producer Brian Eno. Several contemporary artists who engage in sound work were referenced: Montreal and Mexico City-based Rafael Lozano-Hemmer, whose sound sculpture series, entitled 'Sphere Packing'-spheres sized to the composers' o utput, e mitting the totality of their works all at once. The array included Bach, György Ligeti, Richard Wagner, Charles Ives, John Cage, etc.[1] Students related their projects to s mall venues they had visited, from the influential nightclub Berghain in Berlin to the small, independent venue, the Horse Hospital in Bloomsbury, London. In the Toronto context, the precedent of the Toronto Conservatory of Music, and the recent addition to its facilities, the 1,135-seat Koerner Hall by architect Marianne McKenna of KPMB Architects, was an oft-cited reference. as an institution considered influential as well as intensely popular.

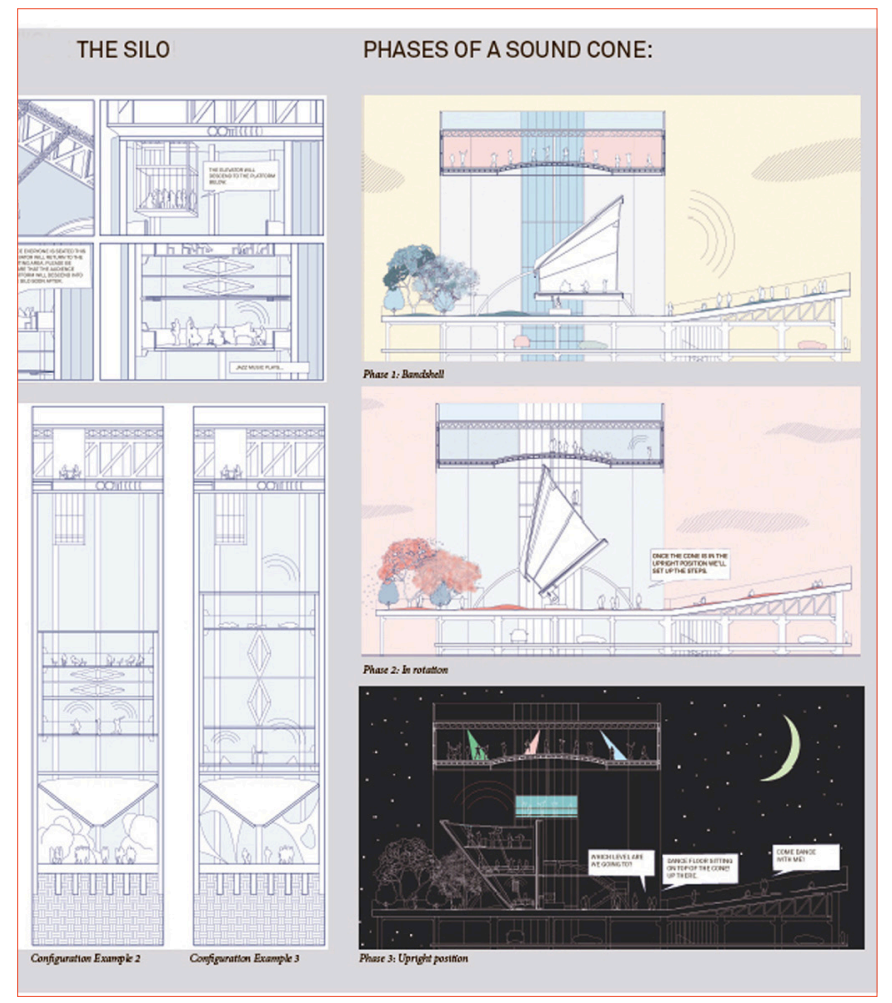

Figure 2. Julia Nakanishi, Strange Visitor, Phases of a sound c one.

\section{URBAN AND SOCIAL CONTEXTS OF DESIGN FOR SOUND}

Traditional popular music halls were viewed as vernacular architecture, and the urban places where they were found were lowerincome, blue-collar neighborhoods. Many cities are exploring ways to attract younger cultural producers, such as musicians and those in the music industry, following the examples of cities such as Austin, Texas; Nashville, Tennessee; Portland, Oregon; Seattle, Washington; Montreal, Quebec and the metropolitan conditions of N ew York, London, Paris, all considered key sites for music and sound work. The possibilities for enhancing their appeal to performers and composers include financing facilities and programming targeting these cultural sectors.

Nashville, a business-oriented music city, accommodates artists with its many local recording studios (estimated at over 300), record labels, (estimated at 80 ), music publishers (an estimated 130). [2] There are some 100 live music clubs, as well as c afés for emerging artists, popular music halls, radio and television coverage of l ocal venues, and m ixed use venues such as musician Jack White's Third Man label, with its own venue and recording facility, or United Record, a l ocal vinyl record pressing factory. Austin, known for its live concert nightlife, has recently partnered with Toronto in order to b olster the Canadian city's nightlife.

Organizations in Montréal include the Pop Montreal Festival, and the SAT, a n o rganization with its own v enue that has recently partnered with the Parisian music hall, the Gaité-Lyrique, 


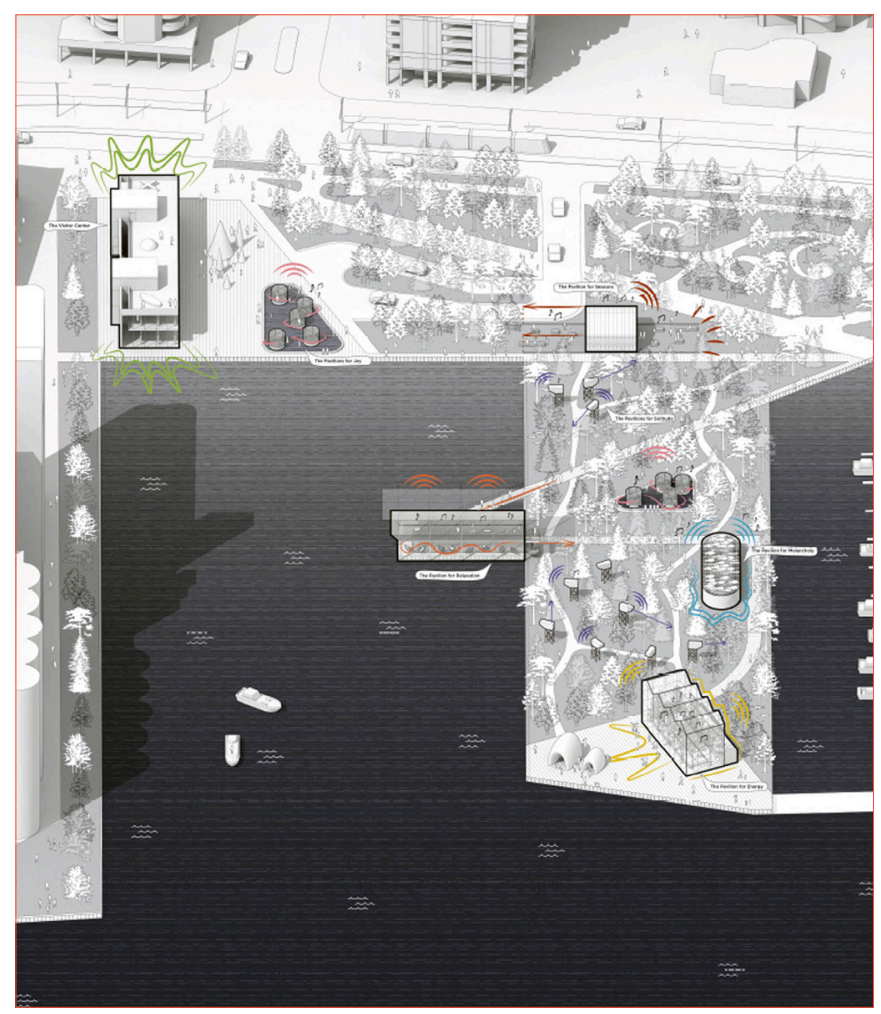

Figure 3. Andy Truong Pham, Toronto Waterfront Music and Therapy Park.

renovated by architect Manuelle Gautrand in 2011. The SAT [Société d'Art et Technologie] provides a significant number, about 200 entry-level intern positions in performance, electronic recording, and research. These developments indicate the significance of a ccess to sound and media creation facilities. Another relevant area in an era of podcasts is that of independent radio SkB Architects designed a n ew facility for KEXP radio in Seattle with performance spaces (planning 400 live shows per year), coffee shop and record store.

\section{PRELIMINARY STUDIO RESEARCH}

The studio work schedule comprised three main e lements: design, field anal sis, and programming. In the analysis phase of the studio, working singly or in small gr oups students selected a composer and presented an appr aisal of the composer's work and influen e to inform and impel the design process throughout the studio. In another facet of the analysis phase of the studio, students explored issues around the location $f$ musical and sound creation and producti $n$ in a seri es of citi s and collected data about the subject, such as diverse venues, artists, audience, recording studios, record labels, e tc. The data translated into a series of maps, diagrams, texts, and preliminary proposals. A field trip to a town or city, and a venue whether small or local, Guelph, Toronto, or farther afield-W indsor-Detroit, Nashville, Cleveland, Memphis, or Montreal, was offered as an o ption, as was an o ption to

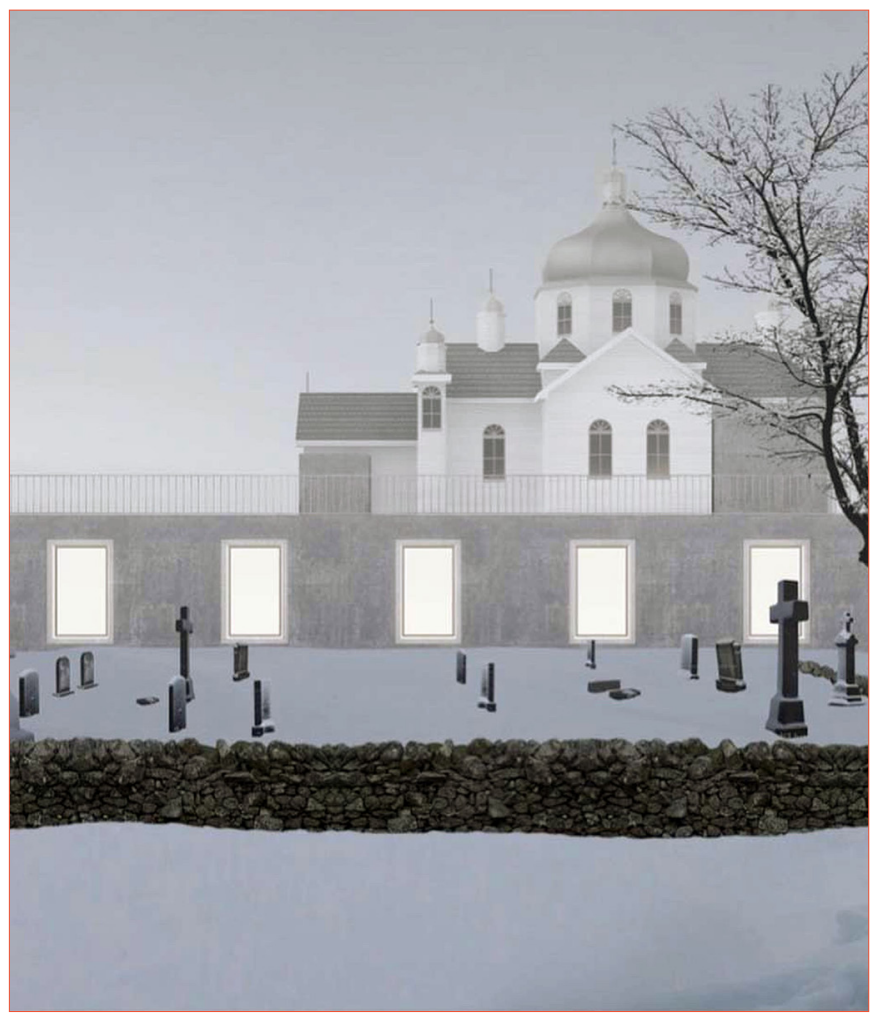

Figure 4. Kyra Ahier, Church Renovation, north f Edmonton, Alberta.

organize an afternoon or early evening musical event. In the early design phase of the studio, the students programmed a p roposition for a building on a s ite of their choice, for a music hall, or venue, or related built form and landscape proposal. Students, several working in teams of two, proposed and designed at first a preliminary proposal, fabricating the scale model of a c omponent space, representative of the whole. The first project, reviewed at the end of the first month of the studio, was a t angible condenser in the modern tradition: an exercise in the design of a listening room, a udition room, interview room, or streaming room. Later the preliminary project was integrated into the design scheme.

\section{DIVERSITY IN PROGRAMMING}

Students choose from an array of studios in third year, to exercise their decision-making skills. To build on that possibility of a r ange of choices the studio asks the students to s eek out sites and elaborate a p rogram.

While preparing research material on which to base a series of choices, there were o pportunities for visiting guest presentations on related topics. In 2016, for example, Paris-based practicing sculptor, Dr. Shuengit Chow, a University of Toronto a rchitecture graduate, presented a prototype qin or guqin instrument: a C hinese zither made in carbon fiber so as to be portable while maintaining its 


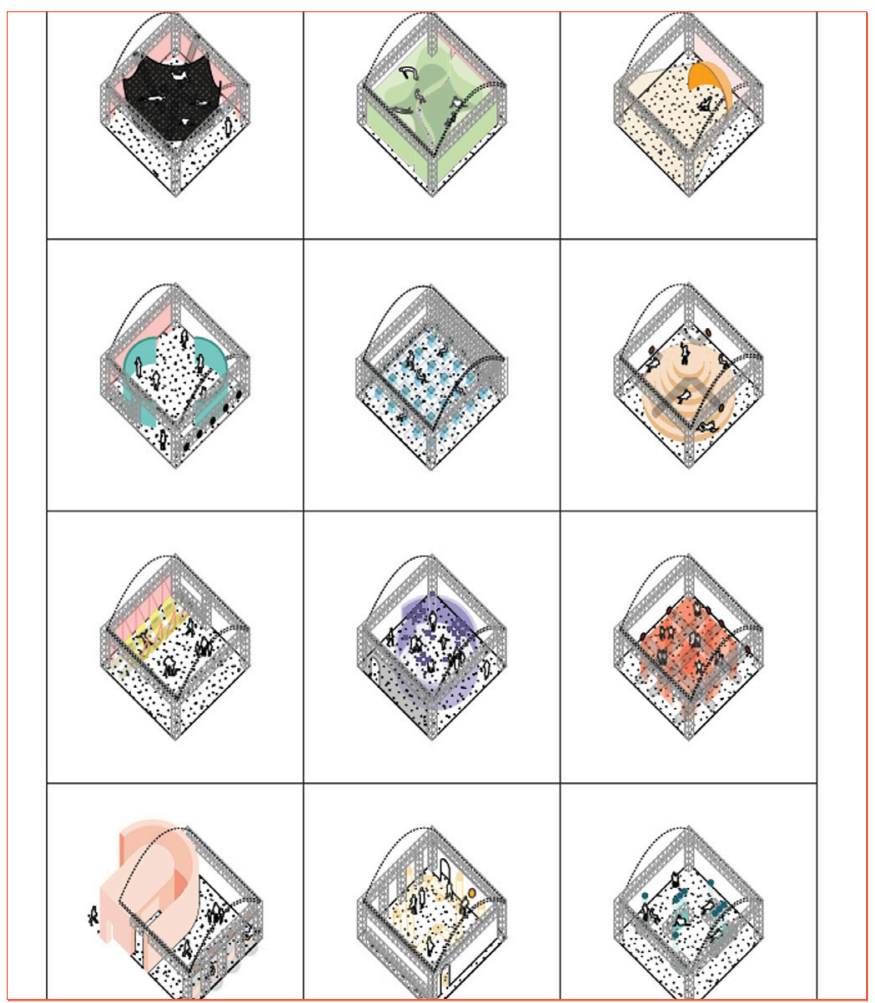

Figure 5. Ruth Yung Lee, Vauxhall Sound System modules, London, UK.

sound quality. Dr. Chow discussed the significance of the instrument in traditional Chinese culture. In 2018 entertainment Lawyer Jared Leon, former programming director of the Montreal Pop Symposium from 2012-2015 addressed the phenomenon of the vanishing venue and discussed issues around booking local venues. Leon is co-publisher and co-editor of the zine, Laura, a p rint publication that includes interviews with music producers, individuals running independant record labels, and booking agents and managers of influential small venues, for example, the nowdefunct Death by Audio in Willamsburg, or the long-running record label, Constellation in Montreal.[3]

In 2016, all sixteen students organized a f ield trip to Detroit, visiting the Detroit Institute Arts and taking advantage of the regular Sunday free jazz afternoon. There was a m orning stopover at the record store, s mall record launch stage and recording booth at the Third Man Record Store in the Cass Corridor. In the refurbished vintage recording booth, a s mall group of three, fit in to cut an impromptu record on the spot.

In both studios, the author co-ordinated, and intern architect Pawel Bednarek taught and reviewed work on a r egular basis, and guest critics included Kurt Kraler in 2016 and Julia Nakanishi, Salim EI Filali and Michal Maciej Bartosik in 2018.

\section{CONSERVATORY OR CLUB}

Some themes emerging from the series of student projects in 2016 included a c ritique of the location and visibility of

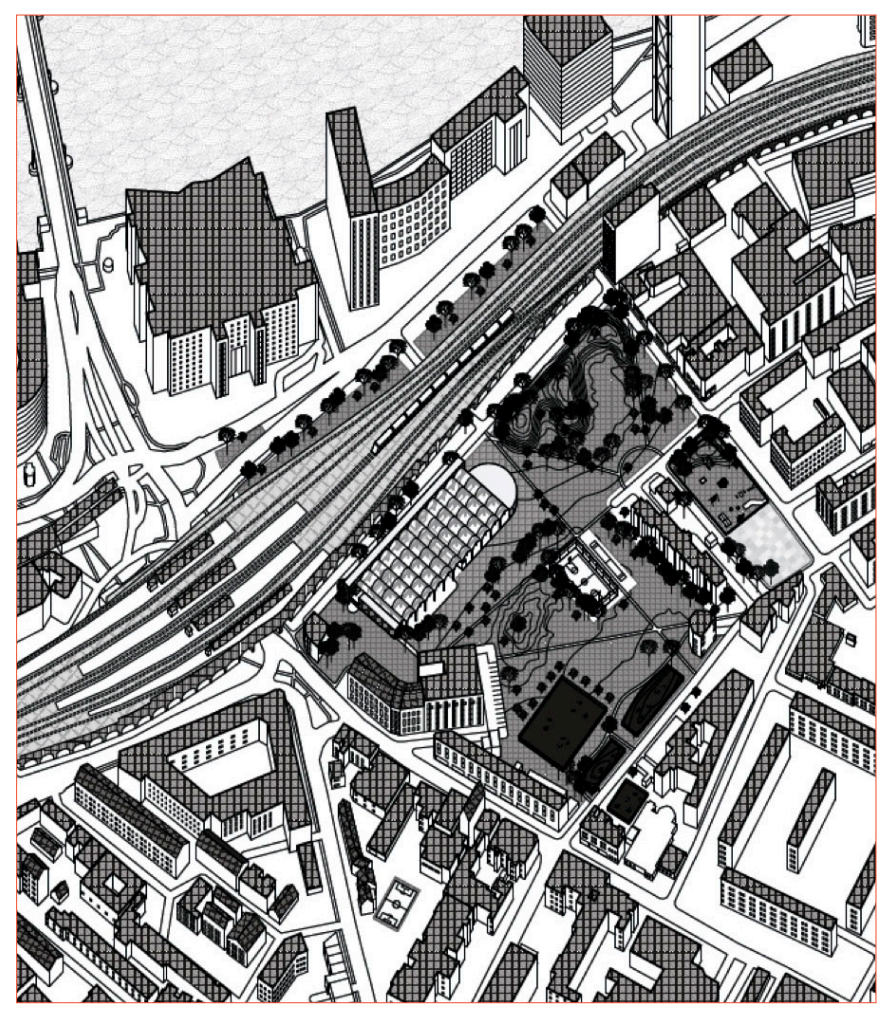

Figure 6. Ruth Yung Lee, Vauxhall Sound System site, London, UK.

performers with respect to the audience. The proposal to renovate a w aterfront silo in Toronto, a s cheme Julia Nakanishi named 'Strange V isitor'- inspired by the music of A phex Twin, the stage name of Richard James, participated in the re-positioning of the role of the frontal stage: her proposal de-emphasized the frontality of performance to privilege the three-dimensional quality of sound. The major program was a $n$ ight-life hub and instrument archive, and featured a I arge, v isible rooftop cone-shaped element that could be repositioned on an axis. The abundance of volume of the silo p rovoked a n innovative new archival function: a s torage place for instruments of various scales that could be used in situ by visiting musicians.

One project set in a na tural landscape was a proposal for a residency and recording studio, Sleeping Bear Studios by Zachary Ropel-Morski. His scheme, inspired by the sounds, songwriting and performance of Su an Stevens, used a small-scale wood frame vocabulary on an island sit e, Big Island, at Oak Lake, situated about half-way between Toronto and $\mathrm{O}$ tt wa, Canada.

Several urban proposals elaborated on contemporary versions of of the classic music conservatory. In 2016 Michelle Meng Xue Lin proposed a M usic Institute near the Cass Corridor district in Detroit. In 2018, Charlotte Damus integrated an existing stone school in the town of C ambridge, O ntario and added a I arge concert hall and music school to the hillside site. The team of $L$ isa Chenron Chen and Mei Yi Chen, the former a classically-trained musician with perfect pitch, worked to propose a music conservatory in downtown Vancouver, making a point to include student 


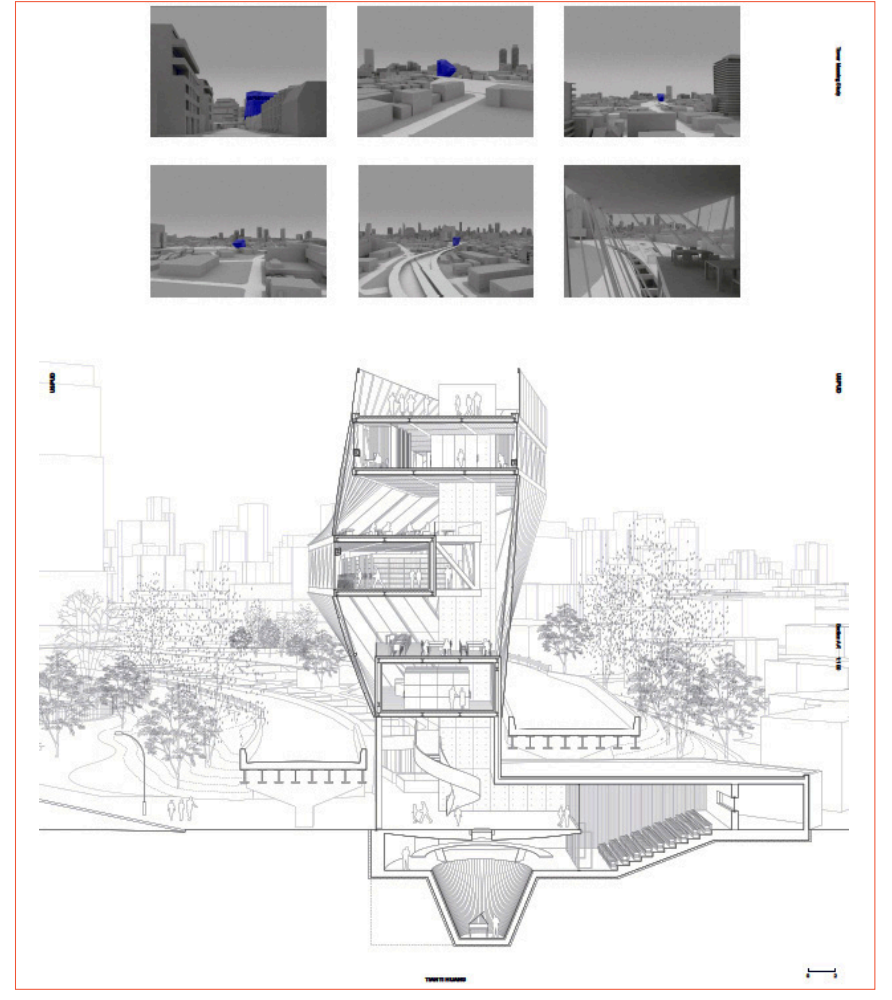

Figure 7. Tianyi Huang, Sound and M usic Research Ins tute, Toronto.

housing in small towers, in a c ontext where housing is not affordable in the centre of the city. Another version of the traditional Conservatory was a m usic school with an auditorium, as a s eries of several raked halls scaled for differing performing events, located the growing Liberty Village district in Toronto by Uarda Kellezi.

In a club proposal celebrating to the indie aesthetic of the solo performer, Grimes, Kate Brownlie proposed an underground nightclub focusing on a circular void. Another below-grade scheme by Dio Yu-chu Su, inspired by the techological sound of Kraftwerk, proposed a transformation of the central Dundas Square in Toronto, re-orienting the mass-culture space of a below-grade parking structure w ith the addition a m ore alternative underground venue, o ne that recognized the consistent presence of a h omeless p opulation in the district. The social mission of the program was a s ignificant aspect of the project for a renovation of a n existing small hotel, the Kormann Hotel on Queen Street east in Toronto by Antonia Ivanova Stanev. Her approach included a s eries of services for Anishinaabe residents, as well as visitors to Toronto, complementing the Queen Street East location of the A nishinaabe Health services center nearby. An independent venue, in the alternative tradition, by Nicole Rak, inspired by the abstract, radiophonic sounds of Delia Derbyshire, proposed the renovation of a typical commercial building on Eglinton Street, transformed into a small-scale DIY-style, and possibly after-hours performance space.

The studio p rojects from 2018 included a b road array of approaches. A theme that emerged from the studio was an interest in creating places where individual and collective wellbeing could be addressed, with a s eries of different programs elaborated by individuals and teams. The design a mbitions extended to the scale of a s mall city. The team of Shiuli Mukerjea and Gerry Jae-Wook Kim proposed a s eries of interventions into both the riverside landscape and the d owntown streetscape of the mid-size O ntario city of London. Interventions that upgraded the overflow and drainage capacities of the river Thames running through London would create riverside performance spaces as well as mitigate seasonal flooding.

Kyra Ahier researched the phenomenon of unused Orthodox wooden churches in Northern A lberta, and proposed renovating a fine example of many unused churches, a dding a new base that would house the Church choir residence, p ractice rooms, and church renovation, on a rural plain north of Edmonton, A lberta. Specific choir activities emphasized chanting and music transcription. Also orienting towards music and spirituality, Ananda Ashram, a y oga center devoted to the ancient practices of yoga and traditional Indian music and dance constituted the program for the design proposal by Shivangi Sundarajan, a s eries of o nestorey stuctures on linear axes, set in a $v$ ast landscape with ongoing soil remediation.

Hannah Carmichael first undertook a g raphic study of thresholds in the Queen Street west nightclub district, leading to an idea to bridge across an existing rail line, stretching the dance music nightclub across the rail infrastructure both above and below, to link the pedestrian destinations by means of an architectural promenade that dramatizes the extended spatial qualities of the site.

Tianyi Huang created a S ound and Music Research Institute, a 'phonometric machine' entitled 'Uspud' after a composition by Erik Satie, featuring an archive tower as billboard, sited on a vacant wedge at the intersection of two fast moving highway offramps in Toronto.

On a site in London south of the Thames, Ruth Yung Lee proposed a s ound park, Vauxhall Sound System, named after the history of the Vauxhall Pleasure Gardens that animated the site from the 17th to the mid-19th century (1661-1859).[4] In the sprawl of London, this metropolitan park, well served by transit at least until midnight, w ould attract nightclubbers from throughout the region, and diversified programming, in an accumulation of domed modules on a m ulti-level grid, would last all night, through to the morning.

For a dense Lower Manhattan site, Rachel Lau proposed a Sound and $V$ ision Cinema A rchive and screening center in a p roject to repurpose a d isused Loew's Cinema on Canal Street, dating from 1926, by the architect Thomas Lamb. Lau's proposal recognized the impact of the cinema soundtrack, p roposing a curatorial component of soundtracks and historic screenings at the archive. A p roject by Andy Truong Pham attached to a related site adjacent to the existing Toronto Music Park, designed in 1999 by cellist Yo-Yo Ma and landscape designer Julie Moir Messervy, and inspired by a composition by Bach, Site no. 1 in G m ajor for 
unaccompanied cello [BVW 1007]. The new park, located on a pier next to a m arina, a dded an exploratory music therapy, a coustic mindfulness, or soundbath, component to the a djacent park.

The richness, variety, and advanced spatial development of the proposals for the sound and place studios, as well as the o pen mix of innovative programming, suggest that emerging designers offer imaginative scenarios for new collective built form and new kinds of architecture for the city. Despite a c ontext of digital connectedness, and faced with the phenomenon of ever-disappearing real venues, [5] a generation of designers continues to envision collective venues and public spaces where it is possible to listen together.

\section{Notes}

1. Rafael Lozano-Hemmer, 'Unstable Presence,' exhibition co-curated by Rudolf Frieling, curator of media arts at SFMOMA, San Francisco Museum of Modern Art, and Leslie Johnstone and François LeTourneux, Musée d'Art Contemporain, Montréal, 24.05.2018 - 09.09.2018. accessed 2019.7.30 https://macm.org/exhibitions/ rafael-lozano-hemmer-unstable-presence/

2. Margaret Littman, 'Why Nashville Is Still America's Music City,' photographs Jake Giles Netter. Dec. 1, 2014. accessed 2019.7.30 https://nextcity.org/features/view/ why-nashville-is-still-americas-music-city

3. Issues of the 'zine Laura can be found at the URL telllaurailoveher.com accessed 2009.30.07

4. David Coke, 'Vauxhall Pleasure Gardens 1661-1859.' accessed 2009.30.07 http://www.vauxhallgardens.com/ vauxhall_gardens_briefhistory_page.html

5. Michael Rancic, 'Vanishing music venues: a progress report.' January 11, 2018. accessed 2009.30.07 https://nowtoronto.com/music/features/ vanishing-music-venues-a-progress-report/

\section{BIBLIOGRAPHY AND REFERENCES}

Attali, Jacques, The Political Economy of Music. Minneapolis: University of Minnesota Press, 2003.

Bonet, François J., The Order of Sounds, a sonorous archipelago. London: Urbanomic, 2016.

Byrne, David, How Music Works. San Francisco:

McSweeney's Books, 2012.

Delia Derbyshire, 'The Delian Mode', documentary, accessed 2019.30.7 https://www.youtube.com/watch?v=nXnmSgaeGAl Obrist, Hans Ulrich, A Brief History of New Music. Zurich:

JP Ringier, 2015.

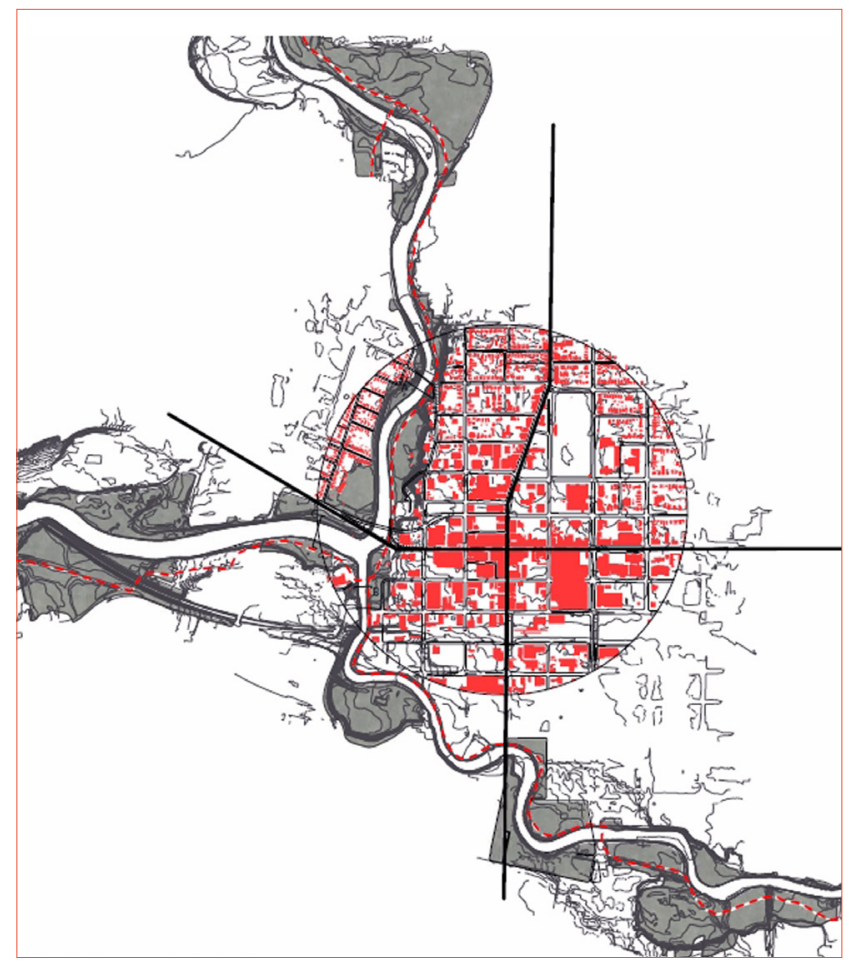

Figure 8. Gerry Jae-Wook Kim and Shiuli Mukerjae, Downtown London and the Thames River, performance site locati ns study, Ontario, Canada. 